\title{
BMJ Open Association between total dose of ritodrine hydrochloride and pulmonary oedema in twin pregnancy: a retrospective cohort study in Japan
}

Satoshi Shinohara, ${ }^{1}$ Rei Sunami, ${ }^{1}$ Yuzo Uchida, ${ }^{1}$ Shuji Hirata, ${ }^{2}$ Kohta Suzuki ${ }^{3}$

To cite: Shinohara S, Sunami R, Uchida Y, et al. Association between total dose of ritodrine hydrochloride and pulmonary oedema in twin pregnancy: a retrospective cohort study in Japan. BMJ Open 2017;7:e018118. doi:10.1136/ bmjopen-2017-018118

- Prepublication history for this paper is available online. To view these files, please visit the journal online (http://dx.doi org/10.1136/bmjopen-2017018118).

Received 7 June 2017

Revised 5 September 2017

Accepted 12 October 2017

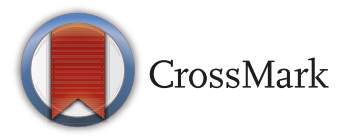

${ }^{1}$ Department of Obstetrics and Gynecology, Yamanashi Prefectural Central Hospital, Kofu, Yamanashi, Japan ${ }^{2}$ Department of Obstetrics and Gynecology, Faculty of Medicine, University of Yamanashi, Chuo, Yamanashi, Japan

${ }^{3}$ Department of Health and Psychosocial Medicine, Aich Medical University School of Medicine, Nagakute, Aichi, Japan

Correspondence to Professor Kohta Suzuki; kohtas@aichi-med-u.ac.jp

\section{ABSTRACT}

Objective Pulmonary oedema is recognised as a severe side effect of ritodrine hydrochloride. Recently, the number of twin pregnancies has been increasing. Few studies have reported the association between total dose of ritodrine hydrochloride prior to delivery and pulmonary oedema in twin pregnancy. We aimed to examine this association and determine the optimal cut-off threshold of total ritodrine hydrochloride dose to predict the incidence of pulmonary oedema in twin pregnancy based on obstetric records. Design Retrospective cohort study.

Setting Yamanashi Prefectural Central Hospital, Japan. Participants Two hundred and twenty-six women with twin pregnancy who delivered at Yamanashi Prefectural Central Hospital between September 2009 and November 2016.

Methods The obstetric records of the participants were analysed. We defined 1 unit of ritodrine hydrochloride as $72 \mathrm{mg}$ per 24 hours continuous transfusion at $50 \mu \mathrm{g} / \mathrm{min}$ to calculate the dose of ritodrine used for tocolysis. Outcome measures Multivariable logistic regression analysis was performed to examine the association between total dose of ritodrine hydrochloride used for threatened preterm labour and pulmonary oedema, while controlling for potential confounding factors. Then, a receiver-operating characteristic curve was used to determine the optimal cut-off of total ritodrine dose to predict pulmonary oedema incidence.

Results Mean maternal age was 32 (range, 18-46) years; 143 participants were nulliparous (63.3\%), 109 had $(48.2 \%)$ term deliveries and $194(85.8 \%)$ had caesarean deliveries. The overall incidence of pulmonary oedema was $13.7 \%$ (31/226). Multivariable analysis showed that the total dose of ritodrine was significantly associated with pulmonary oedema (adjusted OR 1.02; 95\% Cl 1.004 to 1.03). The best cut-off point to predict the incidence of pulmonary oedema was 26 units $(1872 \mathrm{mg})$ (sensitivity, $61.3 \%$; specificity, $87.8 \%$ ).

Conclusion Our results suggest that consideration of the total dose of ritodrine hydrochloride is helpful in the management of patients with threatened preterm labour in twin pregnancy.

\section{INTRODUCTION}

Twin pregnancy arising from assisted reproductive technologies (ART) has been steadily
Strengths and limitations of this study

- To the best of our knowledge, this study is the first to suggest an association between pulmonary oedema and the total dose of ritodrine hydrochloride for tocolysis in twin pregnancies after controlling for some potential risk factors for pulmonary oedema.

- This study was conducted at a single centre. Therefore, a large-scale, multicentre, cohort study is needed to confirm these results in the general population.

- Data regarding sepsis, history of heart disease, endocrine disorders, amniotic fluid embolism, and pulmonary embolism were not considered in this study, although these are potential contributors for pulmonary oedema.

increasing in developed countries, including Japan. ${ }^{1-3}$ Although the total incidence of preterm birth in twin pregnancy is approximately $50 \%,{ }^{4}$ there is no globally established standard treatment for threatened preterm labour. ${ }^{5} \quad \beta 2$-adrenergic agonists, such as ritodrine hydrochloride, are most commonly used for preventing preterm birth worldwide. ${ }^{6}$ Ritodrine hydrochloride is the only agent approved by the US Food and Drug Administration (FDA) for reduction of preterm birth within 48 hours of initiation of treatment. ${ }^{7}$ It is commonly used for threatened preterm labour as a first-line tocolytic agent in Japan, ${ }^{6}$ although the frequency of its use has decreased in other developed countries due to its various side effects. ${ }^{58}$ Of these, pulmonary oedema is known to be the most severe side effect of this drug when continuous intravenous infusion is performed over 1 week. ${ }^{9-11}$ Moreover, previous studies reported that multiple pregnancies are associated with an increased risk of pulmonary oedema. ${ }^{12}{ }^{13}$ However, few studies have focused on the association between the use of ritodrine hydrochloride for threatened 
preterm labour in twin pregnancy and the incidence of pulmonary oedema. The aim of the present study was to examine the association of the total dose of ritodrine hydrochloride and the incidence of pulmonary oedema in twin pregnancy.

\section{METHODS}

\section{Study design}

For this retrospective cohort study, we collected obstetric records and delivery information of 233 women with twin pregnancy who delivered at Yamanashi Prefectural Central Hospital between September 2009 and November 2016. Exclusion criteria were women with single or double fetal demise, major fetal malformations and twin arterial perfusion sequence. This study was reviewed by the Human Subjects Review Committee of Yamanashi Prefectural Central Hospital.

\section{Date collection}

We collected the obstetric data from the medical and operative records. Selected data were maternal age, parity, occurrence of preterm delivery, delivery method (vaginal or caesarean delivery), chorionicity and use of ART (in vitro fertilisation or intracytoplasmic sperm injection). In addition, the presence of pregnancy-induced hypertension (PIH), pregestational weight status, administration of corticosteroids and magnesium sulfate, intraoperative transfusion and postpartum haemorrhage $(\mathrm{PPH})$ were assessed. These factors have been previously described as risk factors for pulmonary oedema in pregnancy. ${ }^{12-14} \mathrm{PPH}$ was defined as 'active bleeding, including amniotic fluid, exceeding $1000 \mathrm{~mL}$ within 24 hours following delivery'. ${ }^{15}$ $\mathrm{PIH}$ was defined as a blood pressure of $\geq 140 / 90 \mathrm{~mm} \mathrm{Hg}$ on at least two occasions. ${ }^{16}$ We also evaluated prolonged bed rest and gestational age, which are reported to affect cardiovascular physiology. ${ }^{17} 18$ Prolonged bed rest was defined as bed rest $>6$ weeks. ${ }^{17}$ Regarding the pregestational weight status, pregestational body mass index (BMI) was calculated according to the WHO standards (bodyweight $(\mathrm{kg}) /$ height $\left(\mathrm{m}^{2}\right)$ ), and patients were classified as obese $\left(\geq 25.0 \mathrm{~kg} / \mathrm{m}^{2}\right)$ or non-obese $\left(<25.0 \mathrm{~kg} / \mathrm{m}^{2}\right)$ according to the Japan Society of Obstetrics and Gynecology Guidelines for Obstetrical Practice 2014. ${ }^{15}$ The criteria for tocolytic therapy include regular or frequent contractions resulting in a demonstrated change of $<25 \mathrm{~mm}$ in transvaginal cervical length or $\geq 20 \mathrm{~mm}$ in cervical dilation. ${ }^{15}$ The dose of ritodrine hydrochloride for tocolysis was determined by each obstetrician. The dose of ritodrine hydrochloride administered intravenously ranged from 50 to $200 \mu \mathrm{g} / \mathrm{min}$, and we defined $1 \mathrm{unit}$ as $72 \mathrm{mg}$ per 24 hours continuous transfusion at $50 \mu \mathrm{g} / \mathrm{min}$. Magnesium sulfate dose ranged from 1 to $2 \mathrm{~g} / \mathrm{h}$ by drip infusion. Pulmonary oedema was defined as the clinical syndrome of acute respiratory distress associated with pulmonary rales, radiographic evidence of alveolar pulmonary oedema and supplemental oxygen
Table 1 Baseline characteristics of the study population

\section{Intravenous Intravenous} administration administration of ritodrine of ritodrine hydrochloride hydrochloride

\begin{tabular}{|c|c|c|c|}
\hline Variables & $(+) n=82$ & $(-) n=144$ & $P$ value \\
\hline $\begin{array}{l}\text { Pulmonary } \\
\text { oedema }\end{array}$ & $22(26.8)$ & $9(6.3)$ & $<0.001$ \\
\hline Maternal age & $32(18-46)$ & $32(23-41)$ & 0.06 \\
\hline Nulliparity & $55(67.1)$ & $88(61.1)$ & 0.37 \\
\hline Preterm birth & $51(62.1)$ & $66(45.1)$ & 0.01 \\
\hline $\begin{array}{l}\text { Caesarean } \\
\text { section }\end{array}$ & $76(92.3)$ & $118(82.0)$ & 0.03 \\
\hline $\begin{array}{l}\text { Prepregnancy } \\
\text { BMI }\end{array}$ & $20.6(16.6-40.9)$ & $19.5(15.8-36.5)$ & 0.003 \\
\hline Monochorionic & $36(43.9)$ & $56(38.9)$ & 0.46 \\
\hline ART & $14(17.1)$ & $26(18.1)$ & 0.85 \\
\hline
\end{tabular}

Values are presented as median (range) or number (\%).

ART, assisted reproductive technology; BMI, body mass index.

requirement to maintain oxygen saturation of the peripheral arteries $>95 \% .^{19}$

\section{Statistical analyses}

First, the Mann-Whitney $\mathrm{U}$ test and the $\mathrm{X}^{2}$ test were used to determine potential confounding factors for pulmonary oedema. Second, a multiple logistic regression model was used to identify variables significantly associated with pulmonary oedema. Then, a receiver-operating characteristic (ROC) curve was used to determine the best cut-off value for the total dose of ritodrine hydrochloride to predict pulmonary oedema. We used the Youden index ${ }^{20}$ which describes the maximum vertical distance between the ROC curve and the diagonal or chance line, to define the optimal cut-off value.

All analyses were performed using bell curve for Excel (Social Survey Research Information, Ltd, Tokyo, Japan), and the significance level was set at $\mathrm{P}<0.05$.

\section{RESULTS}

Due to missing data on ritodrine hydrochloride total dosage $(n=4)$ and single fetal demise $(n=3), 226(96.9 \%)$ women were considered eligible for inclusion in this study. Mean maternal age was 32 (range, 18-46) years, with 143 (63.3\%) women being nulliparous, 109 (48.2\%) having term deliveries and 194 (85.8\%) having caesarean deliveries. The overall incidence of pulmonary oedema was $13.7 \%$ (31/226). Table 1 describes the clinical characteristics of the enrolled women.

The characteristics of the group with intravenous administration of ritodrine versus the group with no intravenous administration of ritodrine were similar, except for a higher incidence of pulmonary oedema, preterm birth and caesarean section and higher prepregnancy BMI in the intravenous administration of ritodrine group. Table 2 reports the distribution of total dose of 
Table 2 Prevalence of pulmonary oedema according to total dose of ritodrine hydrochloride

\begin{tabular}{lc}
\hline $\begin{array}{l}\text { Total dose of ritodrine } \\
\text { hydrochloride (units) }\end{array}$ & Pulmonary oedema, n (\%) \\
\hline $0-10$ & $10 / 157(6.4 \%)$ \\
$11-20$ & $1 / 14(7.1 \%)$ \\
$21-30$ & $5 / 17(29.4 \%)$ \\
$31-40$ & $3 / 6(50.0 \%)$ \\
$41-50$ & $3 / 5(60.0 \%)$ \\
$>51$ & $9 / 27(33.3 \%)$ \\
\hline
\end{tabular}

ritodrine hydrochloride and pulmonary oedema among the entire study population.

Smaller total dose of ritodrine hydrochloride was significantly associated with a lower rate of pulmonary oedema.

On multivariable analyses, the total dose of ritodrine hydrochloride (adjusted OR, 1.02; 95\% CI 1.004 to 1.03), PIH (adjusted OR, 5.51; 95\% CI 1.84 to 16.5) and PPH (adjusted OR, 4.18; 95\% CI 1.14 to 12.4 ) were associated with pulmonary oedema (table 3 ).

ROC curve analysis suggested that the cut-off value of 26 units $(1872 \mathrm{mg}$ ) for the total dose of ritodrine hydrochloride would allow for the maximum number of patients to be correctly classified according to the presence or absence of pulmonary oedema. A cut-off point of 26 units (1872 mg) provided a sensitivity of $61.3 \%$, specificity of $87.8 \%$, positive predictive value of $44.2 \%$ and negative predictive value of $93.4 \%$ (figure 1 ).

\section{DISCUSSION}

Results of this study suggest that there is an association between total dose of ritodrine hydrochloride and pulmonary oedema in twin pregnancy after adjusting for

Table 3 Crude and adjusted ORs of risk factors for pulmonary oedema

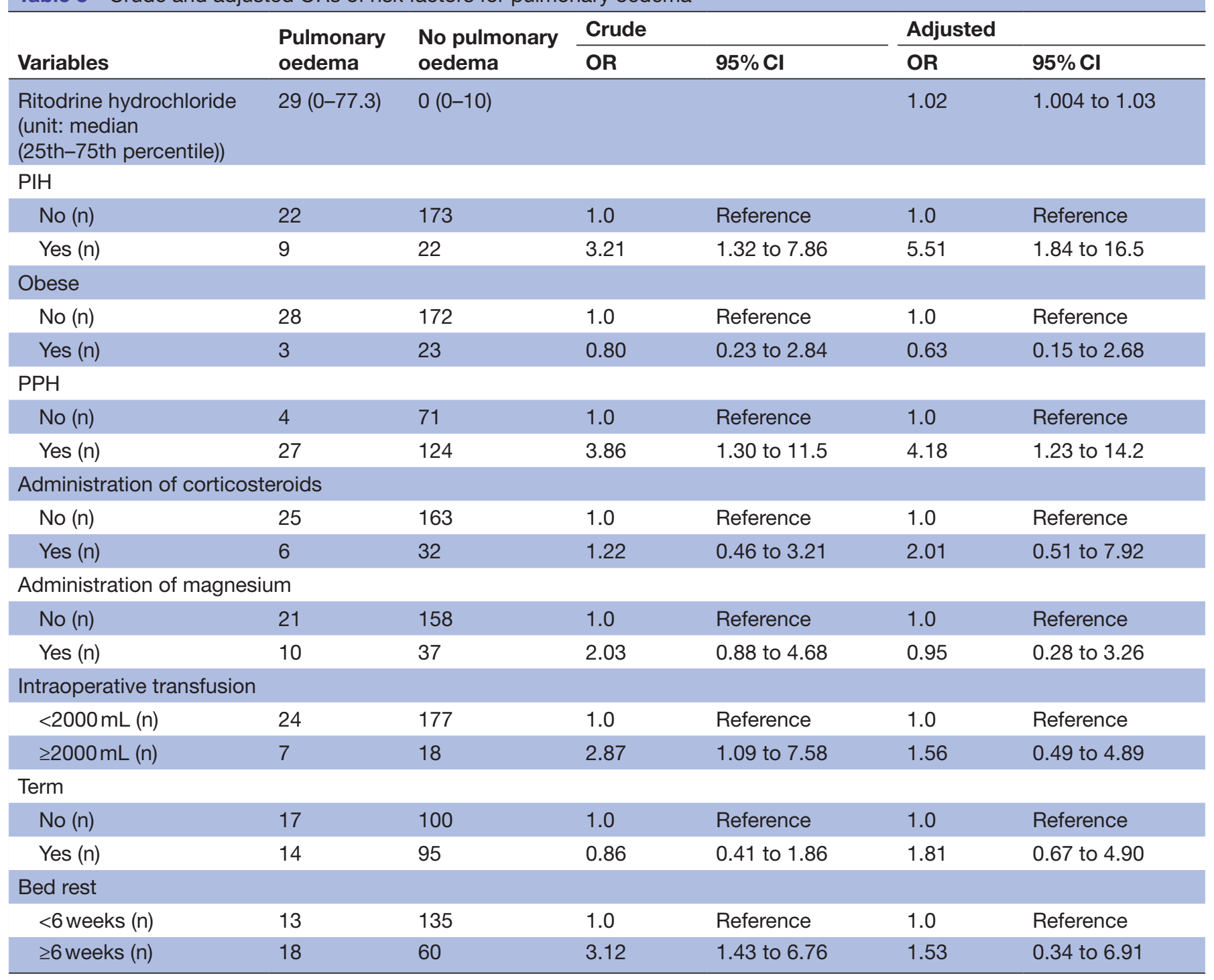

Values are presented as mean \pm SD deviation or number.

$\mathrm{PIH}$, pregnancy-induced hypertension; $\mathrm{PPH}$, postpartum haemorrhage. 


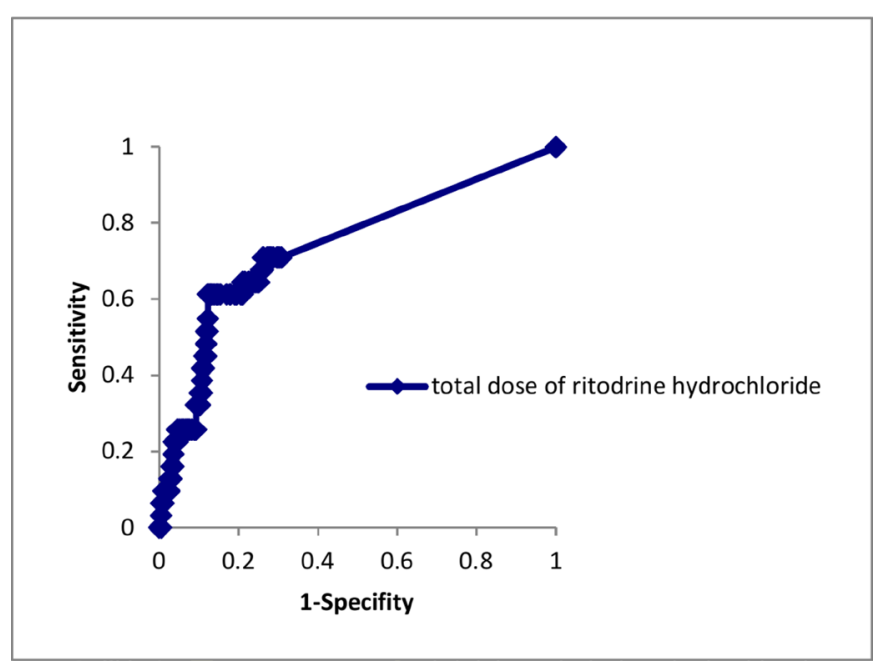

Figure 1 Receiver-operating curve analysis to determine the best cut-off value of total dose of ritodrine hydrochloride for predicting pulmonary oedema.

potential confounding factors. To the best of our knowledge, this is the first study to observe this association and to suggest a threshold optimal cut-off of total ritodrine dose to predict the incidence of pulmonary oedema in twin pregnancy.

First, although treatment for preterm labour with a beta-agonist, including ritodrine, significantly reduces the number of women giving birth within 48 hours and 7 days, ${ }^{21}$ these tocolytic agents can cause serious complications, including pulmonary oedema. There are few studies focused on the association between the dose of ritodrine hydrochloride administered for threatened preterm labour in twin pregnancy and the incidence of pulmonary oedema. Gabriel et al reported that multiple pregnancies dramatically increased the incidence of pulmonary oedema with prolonged intravenous ritodrine hydrochloride therapy. ${ }^{10}$ However, that study was different from our analysis because that report was limited by a small sample size and did not examine the association between the total dose of ritodrine hydrochloride and pulmonary oedema.

Several possible factors are assumed to play a role in the pathophysiology of ritodrine hydrochloride-induced pulmonary oedema. Ritodrine hydrochloride leads to maternal tachycardia and retention of sodium and water by inducing secretion of renin, angiotensin and aldosterone due to its $\beta 2$-adrenergic stimulatory effect. ${ }^{11}$ The desensitisation of $\beta$-adrenergic receptors caused by the prolonged exposure to $\beta 2$ stimulants could disturb the normal response of the heart in physiological status. ${ }^{22} 23$ In addition, in twin pregnancy, maternal cardiac output is increased by $20 \%$ compared with singleton pregnancy at term. ${ }^{24} 25$ The resulting increase in maternal stroke volume and heart rate might lead to myocardial dysfunction and pulmonary oedema. Therefore, the incidence of pulmonary oedema might be increased in proportion to the total dose of ritodrine hydrochloride in twin pregnancy.
The present study showed that the incidence of pulmonary oedema could have been increased by the total dosage of ritodrine hydrochloride, irrespective of the therapeutic duration of this agent in twin pregnancy, and the validated cut-off value of total dosage of ritodrine hydrochloride for predicting pulmonary oedema is 26 units $(1872 \mathrm{mg})$. The maximum dose of ritodrine hydrochloride intravenously injected is limited to $200 \mu \mathrm{g} /$ min in Japan and $350 \mu \mathrm{g} / \mathrm{min}$ in the USA and Canada. ${ }^{6}$ Even if we continue to use ritodrine at $350 \mu \mathrm{g} / \mathrm{min}$ for 48 hours, which is the maximum dose allowed in other countries, the total dose of ritodrine reaches only 14 units $(1008 \mathrm{mg})$. In other words, it can be presumed that ritodrine hydrochloride might be safely used over 48 hours for management of threatened preterm labour in twin pregnancy. In contrast, our results also demonstrate the safety of ritodrine over 1 week within the cut-off value, because the observed negative predictive value of ritodrine total dosage was extremely high (93.4\%). This result might be meaningful for all obstetricians, especially in Japan, where ritodrine hydrochloride is used as the first-line tocolytic agent for threatened preterm labour.

$\mathrm{PIH}$ was also significantly associated with pulmonary oedema. Several studies have reported that twin pregnancy itself is one of the most important risk factors for PIH. ${ }^{1526}$ Impaired endothelial permeability is thought to be a cause of pulmonary oedema in PIH. ${ }^{12}$ Therefore, more attention should be paid to the use of ritodrine hydrochloride in twin pregnancies with suspected PIH. In this study, long-term tocolysis with total dose of ritodrine being >26 units in twin pregnancy with $\mathrm{PIH}$ caused pulmonary oedema in four out of the five $(80.0 \%)$ cases (data not shown).

Our study has several limitations. First, it might be difficult to extrapolate our results to the general population because our study was conducted at a single centre. Therefore, a large-scale, multicentre, cohort study is needed to confirm these results in the general population. Second, data regarding sepsis, history of heart disease, endocrine disorders, amniotic fluid embolism and pulmonary embolism were not included in our statistical model, although these are potential contributors to the incidence of pulmonary oedema. ${ }^{12}$ However, to the best of our knowledge, this study is the first to suggest an association between pulmonary oedema and the total dose of ritodrine hydrochloride for tocolysis in twin pregnancies after controlling for some potential risk factors for pulmonary oedema.

In conclusion, pulmonary oedema was significantly associated with the total dose of ritodrine hydrochloride in twin pregnancy. Accurate risk stratification for pulmonary oedema including consideration of the total dose of ritodrine hydrochloride might improve the management of patients with twin pregnancy and preterm labour.

Contributors SS: data collection. SS and RS: conception or design of the work. SS, RS and KS: data analysis and interpretation; critical revision of the article. SS, RS, YU, SH and KS: drafting of the article and final approval of the version to be published. 
Competing interests None declared.

Ethics approval The Human Subjects Review Committee of Yamanashi Prefectural Central Hospital approved the study design.

Provenance and peer review Not commissioned; externally peer reviewed.

Data sharing statement Extra data can be accessed via the Dryad data repository at http://datadryad.org/ with the doi: 10.5061/dryad.1v8v6.

Open Access This is an Open Access article distributed in accordance with the Creative Commons Attribution Non Commercial (CC BY-NC 4.0) license, which permits others to distribute, remix, adapt, build upon this work non-commercially, and license their derivative works on different terms, provided the original work is properly cited and the use is non-commercial. See: http://creativecommons.org/ licenses/by-nc/4.0/

(c) Article author(s) (or their employer(s) unless otherwise stated in the text of the article) 2017. All rights reserved. No commercial use is permitted unless otherwise expressly granted.

\section{REFERENCES}

1. Wei J, Wu QJ, Zhang TN, et al. Complications in multiple gestation pregnancy: a cross-sectional study of ten maternal-fetal medicine centers in China. Oncotarget 2016;7:30797-803.

2. Pison G, D'Addato AV. Frequency of twin births in developed countries. Twin Res Hum Genet 2006;9:250-9.

3. Geisler ME, O'Mahony A, Meaney S, et al. Obstetric and perinatal outcomes of twin pregnancies conceived following IVF/ ICSI treatment compared with spontaneously conceived twin pregnancies. Eur J Obstet Gynecol Reprod Biol 2014;181:78-83.

4. Elliott JP. Preterm labor in twins and high-order multiples. Clin Perinatol 2007;34:599-609.

5. Haas DM, Caldwell DM, Kirkpatrick P, et al. Tocolytic therapy for preterm delivery: systematic review and network meta-analysis. $B M J$ 2012;345:e6226.

6. Takagi K, Satoh T. Is long-term tocolysis effective for threatened premature labour? J Int Med Res 2009;37:227-39.

7. Kareli D, Pouliliou S, Liberis A, et al. Genotoxic effect of tocolytic drug ritodrine in combination with smoking during pregnancy. $J$ Matern Fetal Neonatal Med 2016;29:1-29.

8. Anon. Treatment of preterm labor with the beta-adrenergic agonist ritodrine. the Canadian preterm labor investigators group. $N$ Engl $J$ Med 1992;30:308-12.
9. Gezginç K, Gül M, Karatayli R, et al. Noncardiogenic pulmonary edema due to ritodrine usage in preterm labor. Taiwan $\mathrm{J}$ Obstet Gynecol 2008;47:101-2.

10. Gabriel R, Harika G, Saniez D, et al. Prolonged intravenous ritodrine therapy: a comparison between multiple and singleton pregnancies. Eur J Obstet Gynecol Reprod Biol 1994;57:65-71.

11. Karaman S, Ozcan O, Akercan F, et al. Pulmonary edema after ritodrine therapy during pregnancy and subsequent cesarean section with epidural anesthesia. Clin Exp Obstet Gynecol 2004;31:67-9.

12. Dennis AT, Solnordal CB. Acute pulmonary oedema in pregnant women. Anaesthesia 2012;67:646-59.

13. Lamont RF. The pathophysiology of pulmonary oedema with the use of beta-agonists. BJOG 2000;107:439-44.

14. Teofili L, Bianchi M, Zanfini BA, et al. Acute lung injury complicating blood transfusion in post-partum hemorrhage: incidence and risk factors. Mediterr J Hematol Infect Dis 2014;6:2014069.

15. Minakami H, Maeda T, Fujii T, et al. Guidelines for obstetrical practice in Japan: Japan Society of Obstetrics and Gynecology (JSOG) and Japan Association of Obstetricians and Gynecologists (JAOG) 2014 edition. J Obstet Gynaecol Res 2014;40:1469-99.

16. Magee LA, Abalos E, von Dadelszen $P$, et al. How to manage hypertension in pregnancy effectively. Br J Clin Pharmacol 2011;72:394-401.

17. Perhonen MA, Franco F, Lane LD, et al. Cardiac atrophy after bed rest and spaceflight. J Appl Physiol 2001;91:645-53.

18. Sanghavi M, Rutherford JD. Cardiovascular physiology of pregnancy. Circulation 2014;130:1003-8.

19. Murray JF. Pulmonary edema: pathophysiology and diagnosis. Int $J$ Tuberc Lung Dis 2011;15:155-60.

20. Perkins NJ, Schisterman EF. The inconsistency of "optimal" cutpoints obtained using two criteria based on the receiver operating characteristic curve. Am J Epidemiol 2006;163:670-5.

21. Neilson JP, West HM, Dowswell T. Betamimetics for inhibiting preterm labour. Cochrane Database Syst Rev 2014;5:CD004352.

22 Hawker F. Pulmonary oedema associated with beta 2-sympathomimetic treatment of premature labour. Anaesth Intensive Care 1984:12:143-51.

23 Tatara T, Morisaki H, Shimada M, et al. Pulmonary edema after longterm beta-adrenergic therapy and cesarean section. Anesth Analg 1995;81:417-8

24 Kuleva M, Youssef A, Maroni E, et al. Maternal cardiac function in normal twin pregnancy: a longitudinal study. Ultrasound Obstet Gynecol 2011;38:575-80.

25 Kametas NA, McAuliffe F, Krampl E, et al. Maternal cardiac function in twin pregnancy. Obstet Gynecol 2003;102:806-15.

26 Duckitt K, Harrington D. Risk factors for pre-eclampsia at antenatal booking: systematic review of controlled studies. BMJ 2005;330:565. 